\title{
Editorial
}

\author{
Salla Sariola
}

You are holding the 30th anniversary issue of Science \& Technology Studies.

With this editorial the journal wishes to thank the readers, authors, reviewers, book reviewers, editors, and the STS community at large for its longstanding presence. Thank you and congratulations S\&TS! At 30 years of age, the journal stands among the oldest STS journals currently published. For example, Science, Technology and Human Values was began in 1967, Social Studies of Science in 1970, Science as Culture in 1987, Science, Technology and Society in 1996, and the Nordic Journal of Science and Technology Studies was published first in 2013.

\section{Beginning and international developments}

The first issue of Science \& Technology Studies was published in 1988, initiated by the Finnish Association of Science and Technology Studies. At start, the journal was entitled Science Studies.

The journal was initiated by an international group with Finnish lead; it was aimed at global audiences but with particular inputs and aims towards strengthening Nordic STS. Science Studies was published biannually in English. In the first issue of the journal (1988), Veronika Stolte-Heiskanen, the first editor articulates this as follows:

\footnotetext{
The last decades have witnessed a growing interest and increased research activity in the field of science studies in the Nordic countries... The (Finnish) Society decided that the time has come to establish a journal in order to disseminate information to an international public about research and ongoing discussion in science studies in Finland and in other Nordic countries...The aim is to eventually institutionalize the journal as a joint Scandinavian publication...our goals are to stimulate and strengthen science studies in the Nordic countries, to intensify contacts and
}

exchange of ideas among scholars working in this field, and to inform the wider international scientific community about science studies carried out in the Nordic environment.

The journal internationalized rapidly, however. In 1994 the Nordic editorial board was complemented with members from beyond Scandinavia, to include, among others, John Ziman. In 2/2005, former Chief Editor Marja Häyrinen-Alestalo writes in an editorial that:

\footnotetext{
The broad perspective that was adopted during the first years was a reflection of analyses made by the journal's Scandinavian authors. Soon, however, we felt a need for broader internationalization. We presented our plans to highly recognised international scholars and asked them to join in the project.
}

Throughout the 2000s, Science Studies grew by both published numbers and diversity: as the number of papers submitted to the journal increased, range of themes and concerns also 
expanded. Hyysalo \& Knuuttila write in an editorial in 2/2009 that " $90 \%$ of our papers and reviewers come from outside Finland."

In 2011, the editorial team welcomed three international new editors, and has increased their number ever since, to the current number of nine editors (one of whom is also the coordinating editor), plus two book editors.

In 2012, the journal became the house journal of the European Association for the Social Study of Science and Technology (EASST). At this point the journal's name was changed to Science \& Technology Studies to reflect its content that also addressed an interest in technologies. Moreover, it was felt important for the editorial team to reflect European diversity: a policy of Europe-wide representation in the editorial team was set in place.

In reflection of EASST's Europe-wide focus, the editorial team now comprises members from all major linguistic and national networks and hubs of STS: Nordic, German speaking, French-speaking, Dutch, British, Southern, and Eastern European regions. The journal does not aim to only to publish work by those situated in European universities, or research focused on Europe, however. The authors' locations underline the international reach of S\&TS. Scholars publishing in S\&TS span from being situated in universities across Argentina, Australia, Austria, Belgium, Brazil, Canada, Croatia, Colombia, Denmark, Estonia, Finland, Germany, Greece, India, Ireland, Israel, Italy, Japan, Mexico, Netherlands, Norway, Portugal, Slovenia, South Africa, Spain, Sri Lanka, Sweden, Switzerland, UK, and US. In terms of numbers, Europe, and north Europe in particular, is strongly present, with also large number of papers coming from Northern America.

As the long list of authors' locations attests to, the journal's content scope is global. Indeed, research is reported from further sites and locations as well: translation of STS concepts across different cultures, epistemic traditions, and systems of practice, also beyond the 'developed world', has been a topic that authors in S\&TS have contributed to, e.g. in the editorial of Global Health and STS special issue in 3/2017; and the prologue by Amit Prasad in 4/2017. Work remains to be done, however, to encourage authors based in African countries to be present in the field and to reflect upon intersectionality in STS, both in the topics of study as well as STS's own knowledge production practices.

\section{Special issues and key debates}

The journal has contributed to new and emerging fields of STS, particularly by giving space to these ideas in special issues. The journal has published 15 special issues during the 30 years covering topics such as: knowledge infrastructures, university-society relations, global health, politics of innovation for environmental sustainability, energy in society, cultural analysis as intervention, gender at scientific work places, standardization and social texture, architecture, open source, feminist technoscience, computer models and simulation, ageing and technology, antiscientific sentiments, and evaluation. Exciting forthcoming special issues include numbers and numbering, citizen science, foreknowledge, and expertise.

Possibly owing to the journal's Nordic roots, arising from countries known for their gender equality, gender has featured prominently in the journal's content and editorial presence. Special issues topics have focused on developing feminist technoscience scholarship at large, and addressed gender relations in academic knowledge production. In addition to the special issues, numerous

Table 1. Author's locations 1988-2018

\begin{tabular}{|l|c|c|c|c|}
\hline Continent & $\mathbf{1 9 8 8 - 1 9 9 8}$ & $\mathbf{1 9 9 9 - 2 0 0 8}$ & $\mathbf{2 0 0 9 - 2 0 1 8}$ & Total \\
\hline Europe & 100 & 120 & 262 & 482 \\
\hline North America & 16 & 28 & 41 & 85 \\
\hline Australia & 3 & 1 & 14 & 18 \\
\hline South America & 7 & 4 & 4 & 15 \\
\hline Asia & 5 & & 5 & 10 \\
\hline Africa & & 1 & & 1 \\
\hline
\end{tabular}




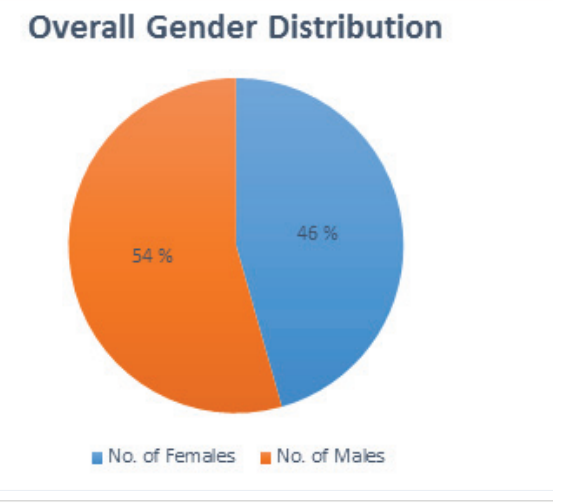

Gender Distribution 1999-2008

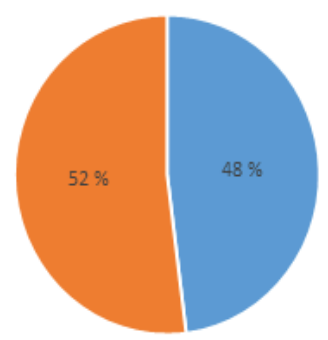

\#No. of Females $\quad$ N No. of Males
Gender Distribution 1988-1998

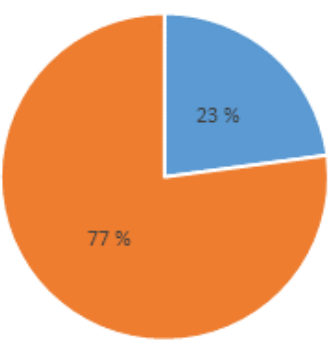

- No. of Females = No. of Males

Gender Distribution 2009-2018

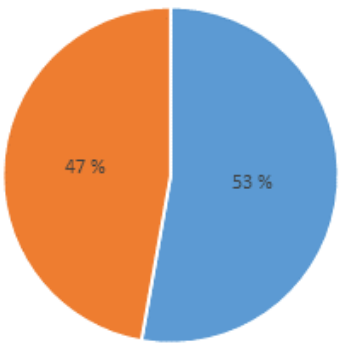

- No. of Females - No. of Males

Figure 1: Gender distribution of S\&TS contributors: the overall distribution and distribution of contributors according to decades. Compiled by Prerna Srigyan.

scholars have emphasized the persisting inequities in science and technology, shown how power operates in research networks, and the ways in which innovations gender and are gendered. If the journal's own numbers are an indication, of the current editorial team, $50 \%$ of the members are women and in the journal's history, four of the six coordinating editors have been women. Of the authors publishing in the journal throughout the 30 years, $46 \%$ have been women. During the first decade, the difference was as unequal as $77 \%$ of men to $23 \%$ women. More recently, however, since year 2009, the number of women authors becomes slightly higher than men at 53\%.

\section{Open knowledge}

The journal is at the forefront open access publishing in STS journals. The entire archive of S\&TS is free to download through the journal website, without embargo on any issues. The journal is also free to publish, meaning that the journal does not charge publication fees from authors. During the early years of the journal's association with EASST, the last issue was reserved for EASST members as a member benefit. The council debated the role of publishing as a 'commons', however, as something that should be available all of those interested in STS as a field, rather than restricted to paying members. As a result of these conversations the embargo was removed and in 2017 the journal became fully open access.

The journal is published without ties to commercial publishing houses. The publication is managed on an open source software based platform called Open Journal Systems (OJS) that is developed by the Public Knowledge Project. Open access is possible thanks to the financial support of EASST and the Finnish Science Foundation via the Finnish Society for Science and Technology Studies.

Once again, thank you for all readers, writers, reviewers, guest editors, and editors of Science \& Technology Studies. For fruitful years ahead! 